\title{
High-Cycle Fatigue Behavior of Pure Iron with Gradient Structures Layer
}

\author{
Yanpeng Feng ${ }^{a}$, Sicong Zhao ${ }^{b}$, Jijia Xie ${ }^{c}$ and Xiaolei Wu ${ }^{d}$ \\ State Key Laboratory of Nonlinear Mechanics, Institute of Mechanics, Chinese Academy of Sciences, \\ Beijing 100190, China \\ afengyanpeng@Inm.imech.ac.cn, ${ }^{\mathrm{b}}$ zhaosicong@126.com, ${ }^{c}$ xiejj@Inm.imech.ac.cn, \\ dxlwu@Inm.imech.ac.cn
}

Keywords: Fatigue, Fatigue crack source, Pure Iron.

\begin{abstract}
In the present study, surface mechanical grinding treatment method was developed to induce a gradient nano-grained structures in commercial pure iron bar. The gradient structures and hardness were characterized by optical microscope and micro-indentation. Fatigue behaviors of samples in gradient nano-grained structures and in as-annealed state were examined at room temperature, and the fatigue fracture behavior was characterized with scanning electron microscope. The result showed that the thickness of deformation layer was about $300 \mu \mathrm{m}$, and the fatigue strength of the treated case was $252 \mathrm{MPa}$ based on fatigue life of $10^{7}$ cycles, but the fatigue strength of the as-annealed sample was $186 \mathrm{MPa}$. Fatigue cracks source of samples in gradient nano-grained structures gradually transformed into the internal of gradient structures layer, but cracks sources of as annealed samples were observed to be initiated at surface.
\end{abstract}

\section{Introduction}

The surface mechanical modifications are characterized principally by in-depth of mechanical, metallurgical, micro-geometrical gradient distributions [1-5]. High cycle fatigue resistance is obtained by the modifications, due to the hardened surface layer and gradient structures. General technologies include shot peening [1], surface mechanical attrition treatment (SMAT) [2,3], surface mechanical grinding treatment (SMGT) [4], carburizing treatment and nitriding treatment et al. Comparing with the latter, SMAT and SMGT can easily realize the microstructures' gradient distribution [5].

Gradient structures have been developed with SMGT, which with gradient nano-grained structures layers, work hardened layer and coarse grain matrix. It is well know that, surface gradient structures could improve the fatigue resistance. However the fatigue failure mechanisms of gradient structures materials is debatable. Clarification of fatigue crack sources initiation mechanisms of samples with gradient structures is crucial for development of surface mechanical modifications. The aim of this work was clarification on this mechanisms in pure metals, without the disturbance of inclusions and different phases.

Pure iron is an important model material for the investigation of characteristic fatigue mechanisms of BCC materials. On the other hand, SMGT is a novel method and first reported in 2011 [6]. Its effects on fatigue behavior were seldom involved. In this work, experimental data were obtained through a cantilever-type rotating bending fatigue tests in atmospheric environment. Subsurface crack initiation and propagation behavior of surface-treated and untreated specimens were investigated.

\section{Experiment procedures}

The materials was a commercial pure iron (DT4) with chemical compositions (in wt \%): C 0.008 , Si 0.020, Mn 0.08, P 0.009, S 0.008, Cr 0.01, Ni 0.01, Cu 0.01, Al 0.16, and balanced by Fe. The received materials were annealed at $900^{\circ} \mathrm{C}$ for 4 hours to get a homogeneous coarse grain structure. Hourglass-shaped fatigue samples were machined. The geometry of samples was shown in fig. 1. 


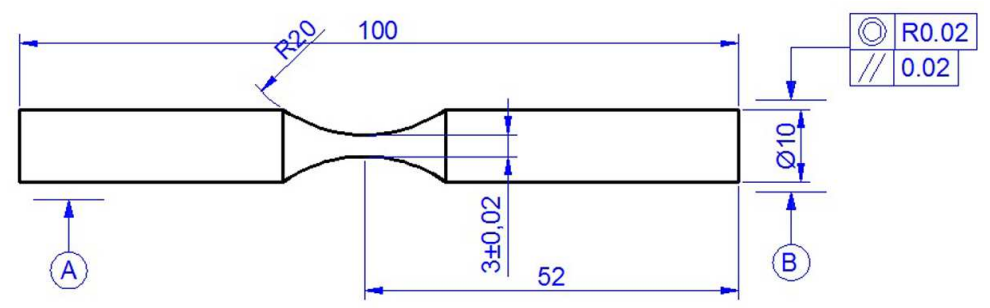

Fig. 1 Sharpe and dimensions of the specimen

Surface mechanical grinding treatment SMGT was developed to synthesize gradient structures on coarse grain iron substrate at about low temperature $\left(-10^{\circ} \mathrm{C}\right)$, which was cold by liquid nitrogen. Only the arc-shaped part in Fig. 2(a) was treated. Schematic diagrams of the treatment and gradient structures were displaced with Fig. 2. The processing parameters are as follows: rotating velocity of the sample $V_{1}=600 \mathrm{rpm}$, sliding velocity of tool tip $\mathrm{V}_{2}=3 \mathrm{~mm} \mathrm{~s}^{-1}$, the penetration depth of the tool tip into the sample is $40 \mu \mathrm{m}$. An arc-shaped WC/Co cemented carbide tool tip with a tip radius of $3 \mathrm{~mm}$ was used. The processing was repeated four times with the same processing parameters. Hardness measurements were carried out on a Mitutoyo MVK-H3 micro-hardness tester with a load of $25 \mathrm{~g}$ and a holding time of 15 seconds.

Fatigue texting method Fatigue experiments was performed at room temperature using a four-axis cantilever type rotary bending fatigue machine, which was operated with rotational speed of 3000 $\mathrm{rpm}(\mathrm{f}=50 \mathrm{~Hz})$. The machine has two spindles driven by one motor and each spindle has specimen holders on both sides. Therefore, four specimens can be tested simultaneously in cantilever-type rotary bending machine. A counterweight applied to the specimen is suspended from the outer end of each specimen by means if a bearing and helical spring.

(a)

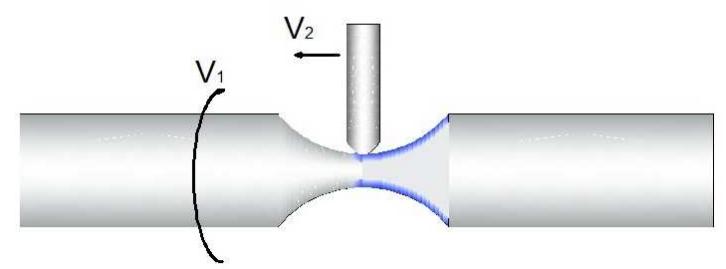

(b)

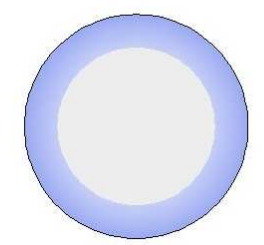

Fig. 2 (a) Schematic illustrations of the surface machine grinding treatment; (b) Schematic diagram of surface gradient structures layers

\section{Results and Discussion}

Fig. 3(a,b) presents the typical optical microstructures of annealed and SMAT. The average grains sizes is about $78 \mu \mathrm{m}$, and second phase is never found for the annealed condition. Quasi-static tension experiments were adopted to investigate the mechanical characters at room temperature and strain rate of $6.0 \times 10^{-4} / \mathrm{s}$. The Result indicated that yield strength of the coarse grain iron was $129 \mathrm{MPa}$, and tensile strength was $302 \mathrm{MPa}$.

After SMGT, the cross section optical microstructures of the surface gradient structures iron were present in Fig. 3(b). From surface to interior, the microstructures were changed from nanocrystalline layer, deformation layer and un-deformation matrix. Fig. 4 displays the Vickers hardness distribution of the surface gradient structures iron, comparing with that of coarse grain case. The hardness in surface layer of gradient structures iron was about $230 \mathrm{Hv}$ about twice of the matrix $120 \mathrm{Hv}$. And the depth of deformated layer was about $300 \mu \mathrm{m}$. 


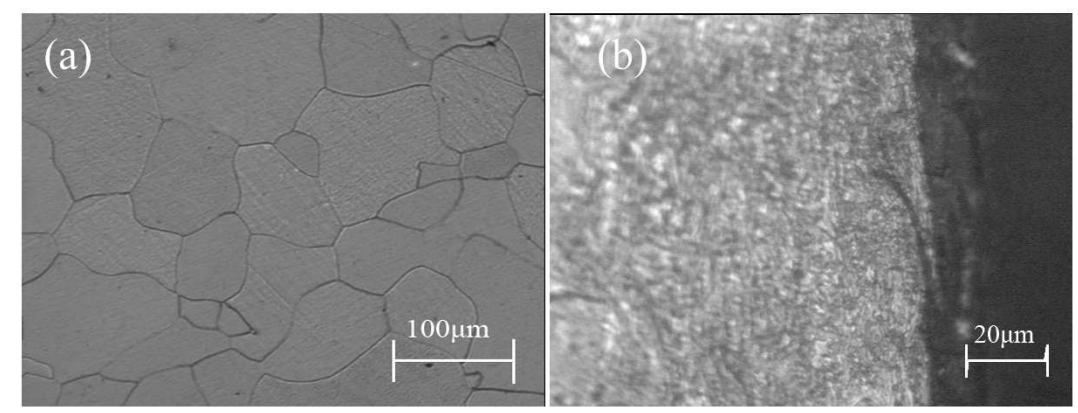

Fig. 3 (a) Microstructures of iron as annealed; (b) Cross section microstructures of SMAT

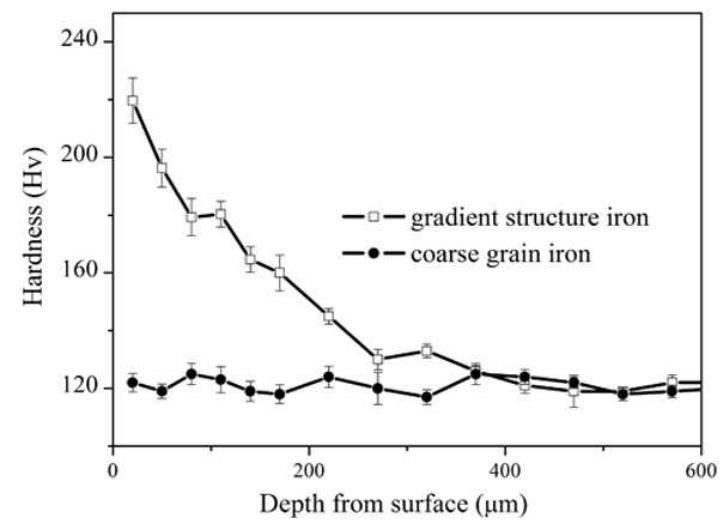

Fig. 4 Micro hardness along the depth of the cross section

Fatigue life The fatigue behaviors were investigated using rotary bending fatigue test at room temperature. Fig 5 show the S-N curves. For homogeneous coarse grain case, the fatigue limited was $182 \mathrm{MPa}$, which is similar with the result of Ferro [7]. Generally there is a relationship between yield strength and fatigue limited base on Ashby's review [8]. In this work, the yield strength of coarse grains iron was $129 \mathrm{MPa}$, Deviation may come from the different deformation rate. The frequency of fatigue test was $50 \mathrm{~Hz}$, and the strain rate of quasi-static tensile was $6.0 \times 10^{-4} / \mathrm{s}$. And iron was a strain rate sensitive material for the different deformation characteristic of crew dislocations in BCC materials $[9,10]$. With gradient structures layers the fatigue strength was improved from $186 \mathrm{MPa}$ to $252 \mathrm{MPa}$. Then how can the gradient structures affect the fatigue behaviors?

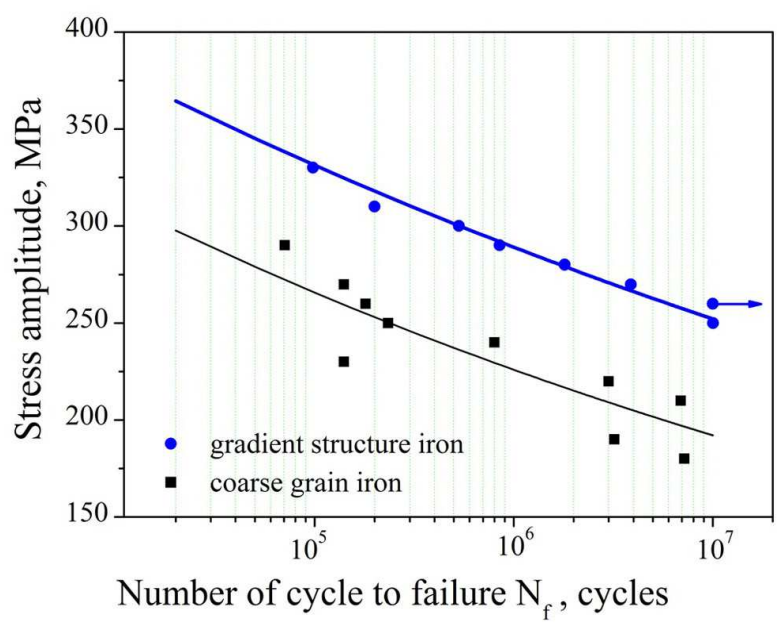

Fig. 5 The S-N curves of cantilever-type rotary bending fatigue tests

Fractography SEM (Scanning electron microscopic) was adopted to observe the fracture surfaces of two cases. Fig. 6 shows the results. For coarse grain iron, all the fatigue cracks were initiated at surface. There are some slip bends in the vicinity of fatigue crack sites. It believed that, the slip bends were formed because of accumulation of dislocations in different glide planes [11]. Due to cycle 
deformation, the forward and backward slipping dislocations in adjacent glide plane get net accumulation. With the evolution of fatigue slip bends, it trend to formed intrusion and extrusion at surface. And the fatigue cracks easy to form at the valley bottom of the intrusion. The results found in this work, were same as the results of Lees' [10].

But things were different for SMGT case as Fig. 6(c)-(e). The fatigue crack initiation positions were different with different stress amplitudes and, of couse the number of cycles to failure. At higher stress amplitude, fatigue cracks were initiated at surface as same as the coarse grain cases. But for lower stress amplitude, the fatigue life increasing, the initiation positions transformed into the internal of the gradient layer. Slip bands were never found nearby the crack initiation positions, and extrusions and intrusions also were never discovered on the surface layers. Fig. 7 displays the statistical measurement of coarse grain and gradient structure iron samples.

Generally, the fatigue crack initiation affected by many factors in polycrystalline materials. Such as impurities, phase boundaries, grain boundaries and accumulation of gliding bands. In this study, for the commercial pure iron, fatigue crack sources were never found at impurities. And second phases were never found too. So the influencing factors of fatigue crack initiation may be the dislocations accumulation and its interactions with grain boundaries. Then how the gradient structures affect the fatigue behaviors?

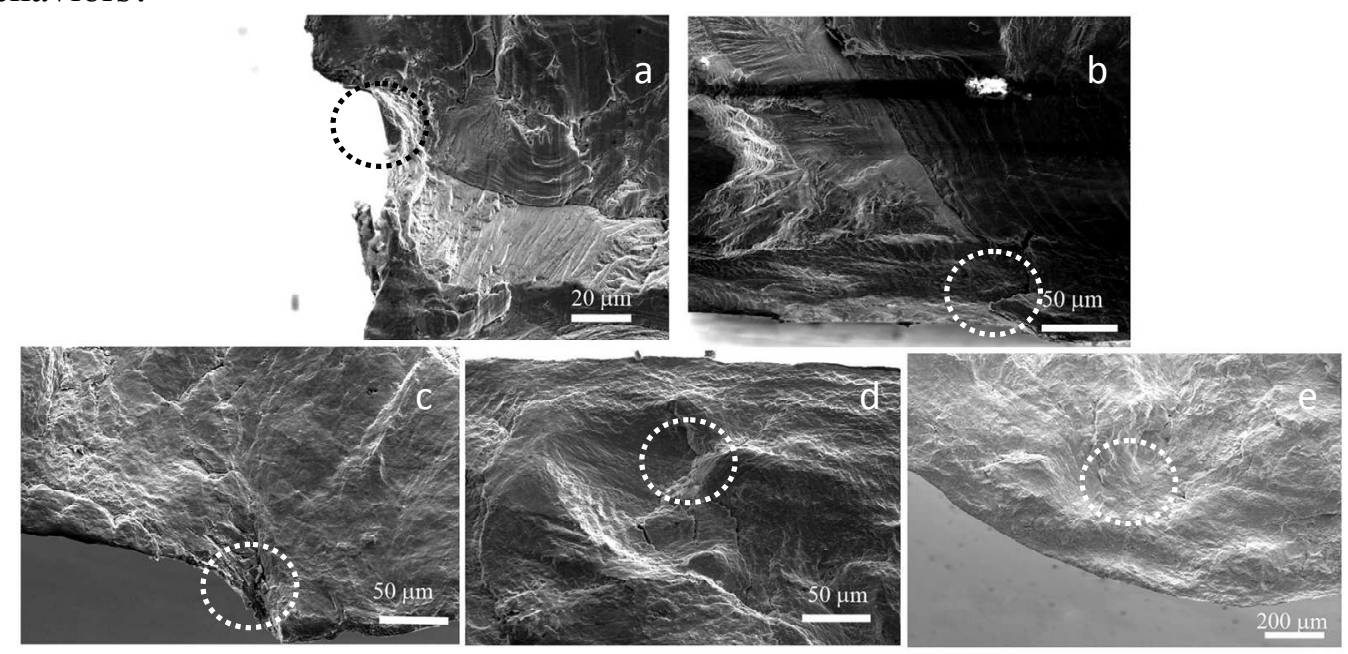

Fig. 6 Crack-initiation positions of coarse grains and gradient structures. Coarse grain: a) $\mathrm{Nf}=5.0 \times 10^{5}$ cycles; b) $\mathrm{Nf}=2.0 \times 10^{6}$ cycles; Gradient structure iron: c) $\mathrm{Nf}=9.8 \times 10^{4}$ cycles; e) $1.0 \times 10^{7}$ cycles

d) $5.4 \times 10^{5}$ cycles;

For coarse grain iron in this study, dislocations accumulation is mainly by the following factors [11]: frictional stress of dislocation move, available slip systems, crystal orientation, shape changes due to asymmetric slip in tension and compression, temperature and strain rate sensitivity. Tanaka and Mura [12] proposed a model describing the initiation of a fatigue crack. The forward and reverse cycle plastic flows cause different signal dislocations move in two closely but different slip systems $[11,13]$. So dislocations accumulation is take place nearby the grain boundaries. The initiation of a fatigue crack is take place by an energy criterion under the assumption that, the accumulation energy of dislocation dipoles must reach a critical value [12]. For coarse grain iron Fig. 6(a) and Fig. 6(b), slip bands easy to form intrusion and extrusion with the forward and reverse plastic flows near the surface. Fatigue cracks were observed at the intrusions sides on the surface layer Fig. 6(a).

However, for gradient structures iron, the obstructive stress or the frictional stress of dislocations in the gradient layer is much high and gradient change from surface layer to matrix. At high stress amplitude, the drive force is large enough to move dislocation, but it is difficult to form regular dislocation configuration like slip bands as coarse grains case, with already existing dislocations and sub-grain boundaries. With the decrease of stress amplitude, it may difficult for dislocations accumulation to reach the critical value at surface layer. And at some weak position internal of gradient structure layers the accumulation can take place and fatigue crack initiated. 


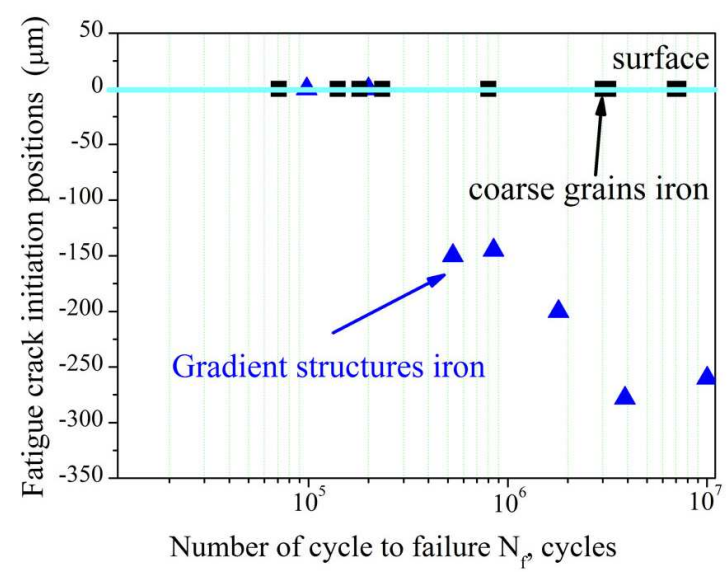

Fig. 7 Statistic the fatigue crack initiation positions of coarse grains and gradient structures iron

\section{Conclusions}

SMAT method was developed to induce gradient structures layers in commercial pure iron bar. Microstructure observation, fatigue tests and fracture analysis led to the following summaries:

1) SMGT improved the fatigue resistance. The fatigue of gradient structures iron was increased significantly from $182 \mathrm{MPa}$ to $252 \mathrm{MPa}$ as compared to that of specimens with coarse grain.

2) On the specimens with gradient structures, the fatigue crack initiation gradually transformed into the interior with the decrease of stress amplitudes.

\section{Acknowledgements}

Authors wish to acknowledge National Natural Science Foundation of China (NSFC) for supporting this research, No: 11002151. National Key Basic Research Planning, Nos: 2012CB932203, 2012CB937500.

\section{References}

[1] K. Dai, L. Shaw, Analysis of fatigue resistance improvements via surface severe plastic deformation. Int. J. Fatigue. 30 (2008) 1398-1408.

[2] N.R. Tao, Z.B. Wang, W.P. Tong, M.L. Sui, J. Lu, K. Lu, An investigation of surface nanocrystallization mechanism in Fe induced by surface mechanical attrition treatment. Acta Mater. 50 (2002) 4603-4616.

[3] T. Roland, D. Retraint, K. Lu, J. Lu, Fatigue life improvement through surface nanostructuring of stainless steel by means of surface mechanical attrition treatment. Scripta Mater. 54 (2006) 1949-1954.

[4] T.H. Fang, W.L. Li, N.R. Tao, K. Lu, Revealing extraordinary intrinsic tensile plasticity in gradient nano-grained copper. Science. 331 (2011) 1587-1590.

[5] K. Shiozawa, L. Lu, Very high-cycle fatigue behavior of shot-peened high-carbon-chromium bearing steel. Fatigue Fract. Engng Mater. Struct. 25 (2002) 813-822.

[6] W.L. Li, N.R. Tao, K. Lu, Fabrication of a gradient nano-micro-structured surface layer on bulk copper by means of a surface mechanical grinding treatment. Scripta Mater. 59 (2008) 546-549.

[7] A. Ferro, G. Montalenti, Fatigue of pure iron and of iron containing a small quantity of carbon after strain ageing, Philosophical Magazine. 8 (1963) 105-119.

[8] N.A. Fleck, K.J. King, M.F. Ashby, The cyclic properties of engineering materials. Acta Mater. 42 (1994) 365-381. 
[9] H.A.Ra, A. Plumtree, The influence of deformation rate on the cyclic behavior of pure iron. Metallurgical transactions. 2 (1971) 1863-1867.

[10] W.J. Lee, Y.W. Chung, M.E. Fine, Effect of environment and grain size on cyclic deformation and surface hardening of iron. Metallurgical Transactions. 19A (1988) 337-344.

[11] S,Suresh, fatigue of materials, second ed.. Cambridge University Press. 1998.

[12] K. Tanaka, A theory of fatigue crack initiation at inclusions. Metall. Trans. A 13 (1982) 117-123.

[13] H. Mughrabi, Fatigue, an everlasting materials problem - still en vogue. Procedia Engineering. 2 (2010) 3-26. 
Advances in Functional and Electronic Materials

10.4028/www.scientific.net/MSF.745-746

\section{High-Cycle Fatigue Behavior of Pure Iron with Gradient Structures Layer}

10.4028/www.scientific.net/MSF.745-746.387

\section{DOI References}

[7] A. Ferro, G. Montalenti, Fatigue of pure iron and of iron containing a small quantity of carbon after strain ageing, Philosophical Magazine. 8 (1963) 105-119.

http://dx.doi.org/10.1080/14786436308212492 